TITLE:

\title{
Amplification of fluorescent DNA through enzymatic incorporation of a highly emissive deoxyguanosine analogue
}

\section{$\operatorname{AUTHOR}(\mathrm{S}):$}

Otomo, Haruka; Park, Soyoung; Yamamoto, Seigi; Sugiyama, Hiroshi

\section{CITATION:}

Otomo, Haruka ...[et al]. Amplification of fluorescent DNA through enzymatic

incorporation of a highly emissive deoxyguanosine analogue. RSC Advances 2014, 4(59): 31341-31344

ISSUE DATE:

2014-07-04

URL:

http://hdl.handle.net/2433/198839

\section{RIGHT:}

This journal is @ The Royal Society of Chemistry 2014.; この論文は出版 社版でありません。引用の際には出版社版をご確認ご利用ください。; This is not the published version. Please cite only the published version. 


\title{
Amplification of Fluorescent DNA through Enzymatic Incorporation of a Highly Emissive Deoxyguanosine Analogue $\dagger$
}

\author{
Haruka Otomo, ${ }^{\text {a }}$ Soyoung Park, ${ }^{*, a}$ Seigi Yamamoto and Hiroshi Sugiyama ${ }^{*, a, b, c}$ \\ s Received (in $X X X, X X X)$ Xth $X X X X X X X X X 20 X X$, Accepted $X$ th $X X X X X X X X X 20 X X$ \\ DOI:
}

\begin{abstract}
A highly emissive thio-analogue of deoxyguanosine triphosphate, ${ }^{\text {th }} \mathrm{dGTP}$, was synthesized and enzymatically incorporated into DNA through primer extension and PCR amplification. The straightforward amplification of ${ }^{\text {th }} \mathrm{dG}$-labeled DNA by natural polymerases by simple addition of ${ }^{\text {th }} \mathrm{dGTP}$ to the standard PCR mix was ${ }_{10}$ demonstrated. The present results will facilitate the broad application of long fluorescent DNA.
\end{abstract}

Fluorescent probes are powerful and indispensable tools with which to detect and monitor biomolecules. Their development combined with fluorescence spectroscopy techniques ${ }^{1}$ is opening up new realm of research, and many biological phenomena have 15 been understood by tracking fluorescent signals in living systems. ${ }^{2}$ For nucleic acids, the development of fluorescent nucleobase analogues has become an important challenge since native nucleic acids are practically non-emissive. ${ }^{3}$ It also has great significance in the viewpoint of the expansion of an 20 artificial genetic molecule with diverse functionality. In this context, many researchers are endeavoring to design and synthesis fluorescent nucleoside surrogates that satisfy versatile photophysical properties and isomorphicity. Recently, Tor and co-workers developed isomorphic fluorescent RNA nucleosides 25 that are characterized by the electronic and structural resemblance to the native nucleosides and have very significant photophysical features, including visible-light emission and high quantum yield. $^{4}$ We have also synthesized a highly emissive deoxyguanosine analogue, th $\mathbf{d G}$ (see Figure 1 (a)), and 30 demonstrated that it can be used to enable the direct visualization of transitions between the B- and Z-forms of DNA as a result of different $\pi$-stacking. ${ }^{5}$ In the previous study, th $\mathbf{d G}$ was synthetically incorporated into the oligonucleotide strands by automated solid-phase synthesis and the application of 35 phosphoramidite chemistry. To further expand the utility of ${ }^{\text {th }} \mathbf{d G}$, we turned to enzymatic incorporation through the use of naturally occurring enzymes and replication systems. ${ }^{6-9}$
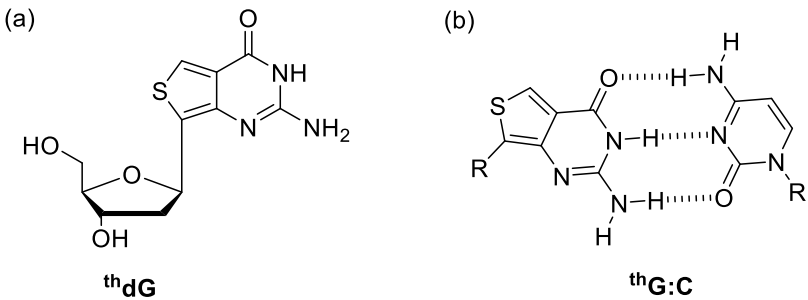

Figure 1. (a) ${ }^{\text {th }} \mathbf{d G}$ monomer. (b) Hydrogen bonding between ${ }^{\text {th }} \mathbf{d G}$ 40 and $d C$ ( $R=2$ '-deoxyribose).
Herein, we report the synthesis of a fluorescent nucleoside triphosphate, ${ }^{\text {th }} \mathbf{d G T P}$, and its enzymatic incorporation into DNA through primer extension and PCR amplification. This study demonstrates that highly emissive ${ }^{\text {th }} \mathbf{d G T P}$ can be recognized and 45 amplified in place of natural dGTP and that the preparation of long fluorescent DNA is feasible using enzymatic approaches and natural DNA polymerases.

The synthesis of th $\mathbf{d G T P}$ was performed by following published procedures for generating ${ }^{\text {th }} \mathbf{d G}^{5}$ and triphosphate nucleoside ${ }_{50}$ derivatives $^{9}$ (Scheme 1). The protected guanosine mimic $O^{5}$ dimethoxytrityl- $N^{2}$-DMF-2-aminothieno[3,4- $\left.d\right]$ pyrimidine deoxynucleoside was synthesized from commercially available methyl 4-aminothiophene-3-carboxylate hydrochloride. The 3'hydroxyl group was protected by acetoxylation, and the 55 dimethoxytrityl protection of the 5 '-hydroxyl group was removed in dichloroacetic acid. The 5'-hydroxyl group was then phosphorylated with 2-chloro-4H-1,3,2-benzodioxaphosphorin-4one and bis(tributylammonium) pyrophosphate following oxidization by $\mathrm{I}_{2}$ solution, and the desired ${ }^{\text {th }}$ dGTP was isolated 60 by HPLC.

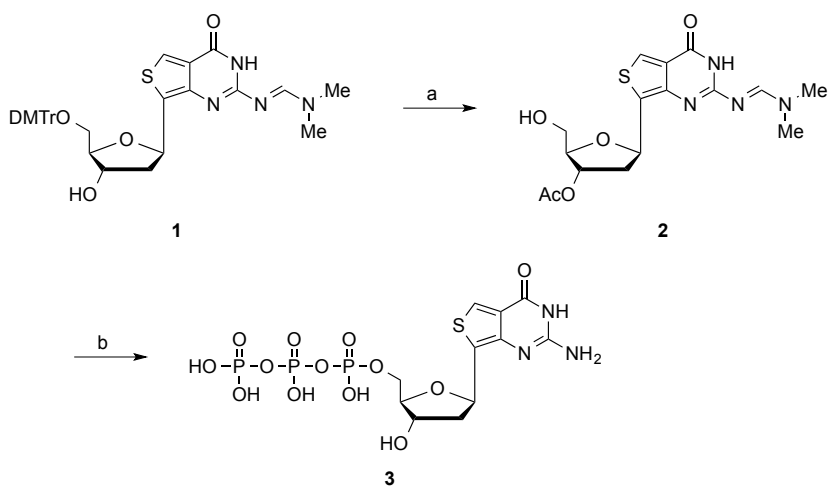

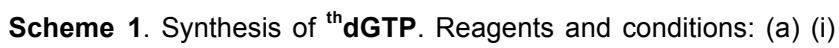
acetic anhydride, pyridine; (ii) dichloroacetic acid, DCM, $0{ }^{\circ} \mathrm{C}, 51 \%$; (b) 2-chloro-4H-1,3,2-benzodioxaphosphorin-4-one, dioxane, ${ }_{65}$ pyridine, tri- $n$-butylamine, bis(tri- $n$-butylammonium)pyrophosphate, DMF, then $\mathrm{I}_{2} /$ pyridine $/ \mathrm{H}_{2} \mathrm{O}, 39 \%$. 
Primer extension involving ${ }^{\text {th }} \mathbf{d G T P}$ incorporation was examined by using the $3^{\prime} \rightarrow 5^{\prime}$ exonuclease-proficient Klenow fragment, a FAM-labeled 10-mer primer, and a 17-mer DNA template 1-3 containing several cytosine residues in the extension area (see ${ }_{5}$ Figure S3). Cytosine residues at the 11th, 14th, or 17th position of the templates served as the paired base for ${ }^{\text {th }} \mathbf{d G}$ (Figure 2a). These primer extension assays were analyzed by determining the length of the extension products using gel electrophoresis. To our delight, primer extension including th ${ }^{\text {thGTP }}$ incorporation

10 opposite to $\mathrm{C}$ gave full-length products. Furthermore, primer extension assays with increasing numbers of th dGTP incorporation positions also proceeded as well as with natural dGTP. To verify the incorporation of ${ }^{\text {th }} \mathbf{d G T P}$ in the DNA, primer extension experiments were conducted with the 10-mer primer 15 without FAM labeling; under these conditions, blue bands in the unstained gel were only observed in the lanes loaded with DNA incorporating ${ }^{\text {th }} \mathbf{d G T P}$ (Figure $2 b$ ).

(a)
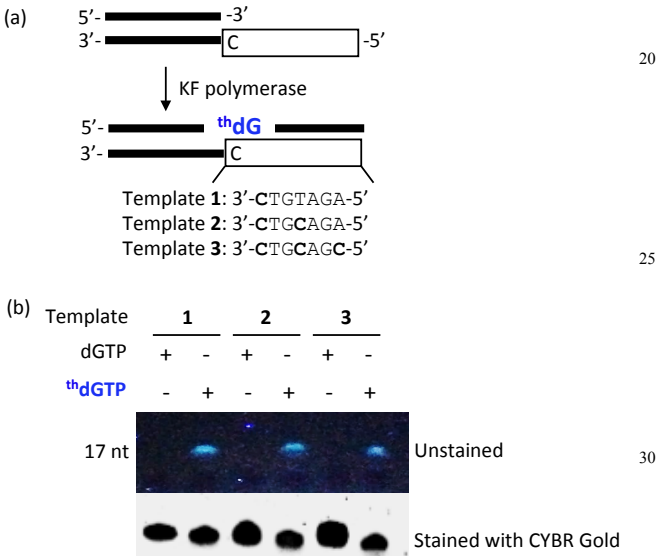

Figure 2. (a) Primer extension experiments with 17-mer templates ${ }_{35} \mathbf{1 - 3}$, in the presence of either natural dGTP or ${ }^{\text {th }}$ dGTP and three dNTPs (dATP, dTTP, and dCTP). (b) Analyses by denaturing gel electrophoresis of primer-extended products using primer without FAM labeling.

${ }_{40}$ We conducted PCR amplification of the template containing only one cytosine in the amplification area with various polymerases,

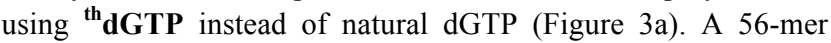
single-stranded DNA template was used together with forward and reverse primers that yield a product of the same length as the 45 template. Throughout all of the experiments conducted in this study, the following PCR cycle was employed: $98^{\circ} \mathrm{C}$ for $2 \mathrm{~min}$, $95{ }^{\circ} \mathrm{C}$ for $15 \mathrm{sec}, 53^{\circ} \mathrm{C}$ for $30 \mathrm{sec}$, and $68^{\circ} \mathrm{C}$ for $10 \mathrm{sec}$. After 40 cycles of PCR, the products were analyzed by native polyacrylamide gel electrophoresis (Figure 3b). KOD -Plus-, ${ }_{50}$ OneTaq, and Deep Vent (exo-) polymerases all gave the fulllength products. However, Deep Vent $\left(\mathrm{exo}^{+}\right)$polymerase gave only low amounts of product. It seems that $3^{\prime} \rightarrow 5^{\prime}$ exonucleasedeficient DNA polymerase is more effective at incorporating th $\mathbf{d G}$. It is interesting to note that in addition to Deep Vent (exo-), 55 which is a $3^{\prime} \rightarrow 5^{\prime}$ exonuclease-deficient DNA polymerase, a high proof-reading polymerase, KOD -Plus-, could also incorporate th $\mathbf{d G T P}$ in place of dGTP.
60

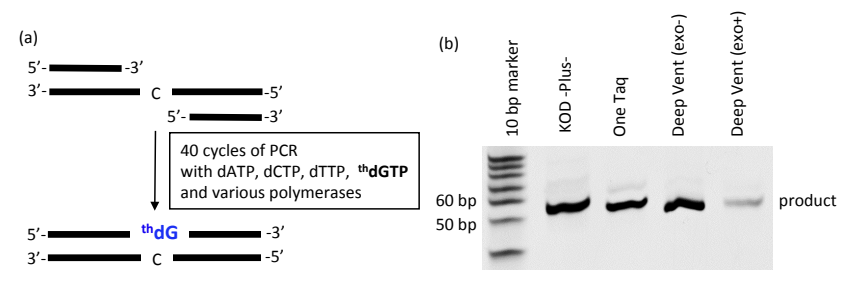

Figure 3. (a) Scheme for PCR amplification experiments using 56mer templates, in the presence of ${ }^{\text {th }}$ dGTP with three dNTPs (dATP, dTTP, and dCTP). (b) Analyses by native PAGE of PCR-amplified products with KOD -Plus-, OneTaq, Deep Vent (exo-), or Deep ${ }_{65}$ Vent (exo+).

These results inspired us to investigate the efficiency of PCR amplification of much longer templates that contain more cytosines as paired bases for ${ }^{\text {th }} \mathbf{d G}$. We first conducted a 338-mer 70 PCR amplification with pET28a plasmid and KOD -Pluspolymerase, using ${ }^{\text {th }} \mathbf{d G T P}$ instead of natural dGTP. However, the desired amplified product was not observed after fractionation by agarose gel electrophoresis, and no products were observed even after a much longer extension time $(20 \mathrm{~min})$. This result suggests 75 that proximal th $\mathbf{d G T P}$ residues are difficult to incorporate consecutively. We therefore conducted PCR amplification using a mixture of dGTP and ${ }^{\text {th }} \mathbf{d G T P}$. Upon increasing the proportion of thdGTP gradually from $1: 1$ to $1: 9$, fluorescent labeling of the long DNA construct was achieved, and PCR products containing ${ }_{80}{ }^{\text {th }}$ dGTP were obtained. The amplified products were fractionated and analyzed by agarose gel electrophoresis. After residual dNTPs were removed using a PCR purification kit (SigmaAldrich), fluorescence spectra were obtained for each DNA solution (Figure 4b).

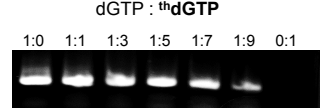

(b)

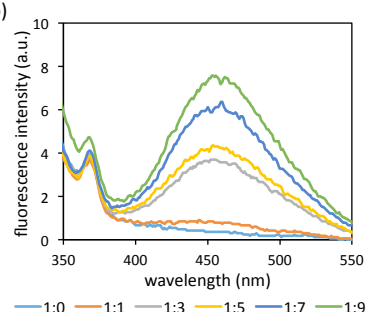

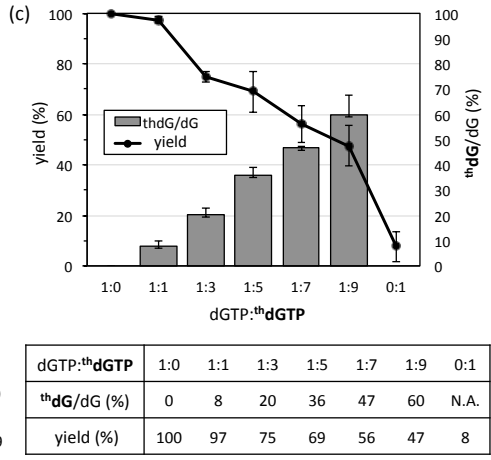

Figure 4. (a) Analyses by agarose gel electrophoresis of amplified 338 bp products. PCR amplification was conducted with dCTP, dTTP, and dATP (200 $\mu \mathrm{M}$ each), and a combined total of $200 \mu \mathrm{M}$ dGTP and ${ }^{\text {th }}$ dGTP mixture (1:0, 1:1, 1:3, 1:5, 1:7, 1:9, and 0:1). (b) ${ }_{90}$ Fluorescence spectra of purified DNA solutions obtained as described in (a) from dGTP $/$ th $d G T P$ nucleotide ratios. All samples contained $3 \mu \mathrm{M}$ DNA. Excitation wavelength was $325 \mathrm{~nm}$. (c) Relationship between the dGTP/ ${ }^{\text {th }}$ dGTP ratio and extent of ${ }^{\text {th }} \mathbf{d G}$ incorporation and the yield of amplified products. Average of three 95 runs. 
It was found that, as expected, the intensity of fluorescence of the purified DNA solution increased with the proportion of ${ }^{\text {th }} \mathbf{d G T P}$. This indicated that a substantial amount of thdGTP was incorporated during PCR. To gain a more detailed understanding, 5 the amplified DNA products were hydrolyzed and the respective amounts of constituent nucleosides were evaluated quantitatively. The amount of th $\mathbf{d G}$ was deduced using a standard HPLC chart obtained by injecting equimolar amounts of nucleosides including thdG. After enzymatic hydrolysis, HPLC analyses indicated that 10 the ratio of ${ }^{\text {th }} \mathbf{d G}$ to $\mathrm{dG}$ in the amplified products increased with the ${ }^{\text {th }} \mathbf{d G T P / d G T P}$ ratio as shown in Figure 4c, although the yield of the amplification product diminished. This result implies that the ratio of th $\mathbf{d G T P}$ to dGTP should be adjusted according to the intended purpose. Encouraged by these results, we established a 15 simple enzymatic method with which to incorporate ${ }^{\text {th }} \mathbf{d G}$ into DNA by simply adding ${ }^{\text {th }} \mathbf{d G T P}$ ( 5 equiv) into the standard PCR reaction mixture. To investigate the scope of the system with respect to the amplified products, we conducted PCR amplification of 298-, 480-, and 761-mer DNA using pGEM or ${ }_{20}$ pUC18 plasmids with other sets of primers. As a result, fluorescent products of the expected length were obtained that were labeled by ${ }^{\text {th }} \mathbf{d G}$ (Figure 5).

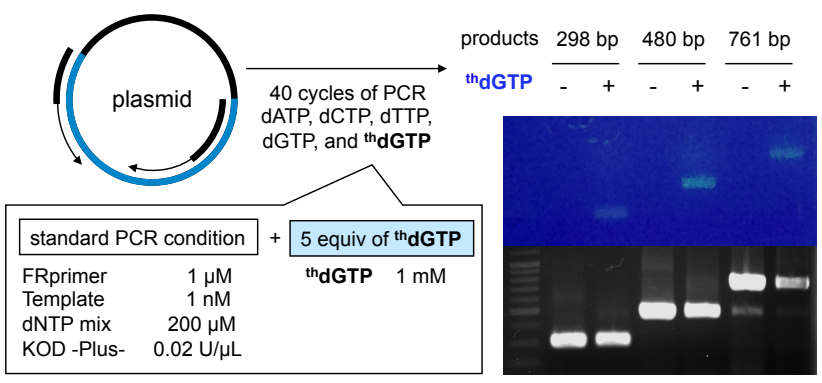

Figure 5. Simple ${ }^{\text {th }} \mathbf{d G}$ labeling for long fluorescent DNA. Analyses 25 by agarose gel electrophoresis of PCR-amplified products; ${ }^{\text {th }}$ dGTP (5 equiv, $1 \mathrm{mM}$ ) was added to $200 \mu \mathrm{M}$ dNTPs (dCTP, dTTP, dATP, and (GTP) and standard PCR reaction mixture. Photograph taken (top) under $254 \mathrm{~nm}$ irradiation before staining, and (bottom) after staining with ethidium bromide.

In conclusion, we have synthesized a visible fluorescent nucleoside triphosphate, ${ }^{\text {th }} \mathbf{d G T P}$, and incorporated it into DNA through primer extension and PCR amplification. ${ }^{\text {th }} \mathbf{d G T P}$ can be incorporated into DNA with only slightly lower efficiency than 35 natural substrate dGTP, and straightforward addition of ${ }^{\text {th }}$ dGTP into the standard PCR mixture gives emissive ${ }^{\text {th }} \mathbf{d G}$-labeled DNA strands that can be observed under UV irradiation with the naked eye. We expect that this methodology, which keeps the inherent structure of DNA intact, will facilitate the application of long 40 fluorescent DNA in areas such as the construction of fluorescent DNA nanostructures. Furthermore, these results raise the intriguing possibility that ${ }^{\text {th }} \mathbf{d G}$ could be incorporated into living cells as a fluorescent probe. ${ }^{10,11}$

\section{Notes and references}

${ }_{45}{ }^{a}$ Department of Chemistry, Graduate School of Science, Kyoto University, Kitashirakawa-oiwakecho, Sakyo-ku, Kyoto 606-8502, Japan ${ }^{b}$ Institute for Integrated Cell-Material Sciences (iCeMS), Kyoto University,
Yoshida-ushinomiyacho, Sakyo-ku, Kyoto 606-8501, Japan ${ }^{c} C R E S T$, Japan Science and Technology Corporation (JST), Sanbancho, Chiyoda50 ku, Tokyo 102-0075, Japan. Fax: (+)81-75-753-3670; Tel.: (+)81-75753-4002;E-mail: hs@kuchem.kyoto-u.ac.jp

$\dagger$ Electronic Supplementary Information (ESI) available: [details of any supplementary information available should be included here]. See DOI: $10.1039 / \mathrm{b} 000000 \mathrm{x} /$

55 Acknowledgements: We express our sincere thanks for the CREST grant from the Japan Science and Technology Corporation (JST), grants from the WPI program (iCeMS, Kyoto University), and for the global COE program from the Ministry of Education, Culture, Sports, Science and Technology (MEXT), Japan. We thank Fumitaka Hashiya for his help and 60 useful discussions. The authors acknowledge referees for suggestions that resulted in an improved manuscript.

1 a) J. R. Lakowicz, Principles of fluorescence spectroscopy, $3^{\text {rd }}$ ed., Springer, New York, 2006; b) B. Valeur, Molecular fluorescence, principles and applications, Wiley-VCH, Weinheim, 2002.

2 a) G. Mayer, A. Heckel, Angew. Chem., Int. Ed. 2006, 45, 49004921; b) R. W. Sinkeldam, N. J. Greco, Y. Tor, Chem. Rev. 2010, 110, 2579-2619.

3 Recent reviews; a) M. E. Hawkins, L. Brand, M. L. Johnson, Methods Enzymol. 2008, 450, 201 - 231; b) D.W. Dodd, R. H. E. Hudson, Mini-Rev. Org. Chem. 2009, 6, 378-391; c) Y. Tor, Pure Appl. Chem. 2009, 81, 263-272; d) L. M. Wilhelmsson, Q. Rev. Biophys. 2010, 43, 159-183; e) M. Kimoto, R. S. I. Cox, I. Hirao, Expert Rev. Mol. Diagn. 2011, 11, 321-331; f) R.W. Sinkeldam,N. J. Greco, Y. Tor, Chem. Rev. 2010, 110, 2579-2619.

4 a) D. Shin, R. W. Sinkeldam, Tor, Y. J. Am. Chem. Soc. 2011, 133, 14912-14915; b) Y. Tor, S. D. Valle, D. Jaramillo, S. G. Srivatsan, A. Rios, H. Weizman, Tetrahedron 2007, 63, 3608-3614; c) N. J. Greco, Y. Tor, Tetrahedron 2007, 63, 3515-3527; d) R.W. Sinkeldam, L. S. McCoy, D. Shin, Y. Tor, Angew. Chem., Int. Ed. 2013, 52, 1-6.

5 S. Park, H. Otomo, L. Zheng, H. Sugiyama, Chem. Comm., 2014, 50, 1573-1575.

6 Y. Tor, P. B. Darvan, J. Am. Chem. Soc. 1993, 115, 461-4467.

857 J. Chelliserrykattil, H. Lu, A. H. F. Lee, E. T. Kool, Chem. Bio. Chem, 2008, 9, 2976-2980.

8 K. Kino, K. Sugasawa, T. Mizuno, T. Bando, H. Sugiyama, M. Akita, H. Miyazawa, F. Hanaoka. Chem. Bio. Chem, 2009, 10, 2613-2616

9 M. Kimoto, T. Mitsui, S. Yokohama, I. Hirao. J. Am. Chem. Soc. 2010, 132, 4988-4989.

10 Examples of fluorescent detection of DNA origami nanostructure using intercalators or fluorophores modified DNA; (a) H. Ö zhalıc1Ü nal, B. A. Armitage, ACS nano, 2009, 2, 425-433. (b) X. Shen, Q. Jiang, J. Wang, L, Dai, G. Zou, Z. Wang, W. Chen, W. Jiang, B. Ding, Chem. Commun., 2012, 48, 11301-11303. (c) V. J. Schüller, S. Heidegger, N. Sandholzer, P. C. Nickels, N. A. Suhartha, S. Endres, C. Bourquin, T. Liedl, ACS nano, 2011, 5, 9696-9702. (d) G. Zhua, J. Zhenga, E. Songb, M. Donovana, K. Zhangb, C. Liue, W. Tan, PNAS, 2013, 20, 7999-8003.

10011 Example of incorporation of nucleoside analogue into the living cells; C. Y. Jao, A. Salic, PNAS, 2008, 41, 15779-15784. 